\section{GILA MONSTERS.}

BY D. A. WILLEY.

The Gila monster of the United States has been well named by the naturalist Heloderma suspectum, for the reason that it has been a subject of discussion for fully interesting of the reptile family in the United States, for in spite of the investigations which have been for in spite of the investigations which have been
made authorities still differ as to whether its bite is made authorities still dister poisons or not.

In addition to the variety found in the States, anoth er called the Heloderma horridum is found in Mexico. Indians and Mexicans residing in the localities where the monsters have been captured, sincerely believe that their bite is fatal to a human being; but so far as known no person has ever died from the effects, although many cases are recorded of people being bitten. These peculiar lizards are found principally in Arizona, New Mexico, northwestern Texas, while a few have been seen in Southern California. They are most numerous in the Mohave desert of Arizona, also along the San Pedro and Mohave rivers, while the Mexican variety has its habitat chiefly in the State of Sonora. The lizards are found not only in the arid valleys, but at a comparatively high elevation, a proof that they are extremely hardy and can endure a considerable range of temperature. The extent of the territory in which they are found has enabled naturalists to secure a comparatively large number alive, and as already stated, their habits have been closely observed by naturalists, not only in this country but abroad.

The species in the Southwest form a distinct contrast to any other variety of lizard on account of the size, which, as is indicated by the photograph, is mammoth in contrast to the ordinary desert lizard, which is seldom as long as one's hand. The head is very prominent, comprising about one-fifth of the total length of the body. Like the back it is thickly covered with tubercles, forming a sort of armor. In the full-grown monster, these tubercles are tinted yellow and black The exterior of the stomach and the surface under the tail are also protected, but by scales. One of the peculiarities of the lizard family is that the bones of the tail are extremely fragile, and this appendage frequently becomes detached by accident or when bitten by ly becomes detached by accident or when bitten by
some animal. The Gila monster, however, differs in this respect, as its skin is so tough that the tail forms one of the strongest portions of its body. In fact, it can raise itself to a considerable height with its powerful fore-legs, balancing itself on the tip of the tail, thus enabling it to climb rocks and other steep ascents.

One of the most interesting features of its anatomy, and the one which has given rise to so much discussion as to its venomous qualities, is its teeth. Each jaw has from eight to ten, which are long, conical, and slightly recurved. Each tooth, however, contains a deep furrow extending from the sharp point to its base, terminating in a duct connecting with glands. This formation is so similar to that of venomous snakes, that it has been advanced as proof that the bite of the heloderma is poisonous. The teeth are so deeply imbedded in flesh that ordinarily only the points are revealed, but the grooves are so large that the saliva contained in the glands readily exudes. Naturalists who have made a study of the many varieties of the lizard family are of the opinion that this is the only one which has teeth. Consequently, interest has been increase in a study of its anatomy, and among those who have given opinions relative to the effects of its bite are some of the most noted authorities of this country and Europe. With the exception of the teeth and glands, however, the monster bears little resemblance to any variety of snake either poisonous or otherwise. It is very slow and clumsy in its motions on account of its shape. It is not timid like other reptiles, however, and when threatened with a stick will endeavor to grip it in its jaws, and if it seizes the stick, will hold on like a dog. When angered it emits its breath in a succession of quick gasps. The breath is very fetid, and its odor can be detected at some little distance from the lizard. It is supposed that this is one way in which the monster catches the insects and small animals which form a part of its food supplythe foul gas overcoming them.

In 1857 the Heloderma suspectum was made the subject of study by Dr. John Gray, of the British Museum. Prof. E. D. Cope, the eminent American anatomist, made a study of the salivary glands in the lower jaws and discovere their connection with the grooves in the teeth. Prof. Cope, however, failed to find that the glands were similar to those of poisonous snakes. On the other hand, Dr. S. Weir Mitchell and Dr. Edward T. Reichert made a series of experiments upon reptiles and small mammals. Saliva was injected into them by a hypodermic syringe, with a result that all died in a few minutes. From these and other experiments the naturalists drew the conclusion that the saliva was fatal, at least to birds and small animals. Dr. H. C. Yarrow at Tucson, Arizona, practically repeated the experiments made by Dr. Mitchell and Dr. Reichert, using chickens and rabbits, but in every case the victims recovered.
One of the instances where the Gila monster has bitten a human being is that of $\mathrm{Dr}$. R. W. Shufeldt, who was thus injured while at work in the American National Museum at Washington. Realizing the opportunity to study the effects of the bite, Dr. Shufeldt closely observed the symptoms. The wound, however, healed in a few days, and apparently had no other ill results than the laceration caused by the teeth. Dr. Shufeldt perceive no symptoms of poisoning. Another instance of the effect of the bite of the Gila monster on animals and reptiles was noted in the Zoological Garden at London, where one of the monsters from America became enraged for "some reason, and bit a frog and a guinea pig. Both died in a few minutes, apparently from the effects of poison. One reason why this interesting lizard is so feared by the natives of the Southwest is undoubtedly because of its repulsive appearance, but it has actually been tamed, so to speak and instances are known where it would take food from the hand of its owner, crawling along the arm and shoulder without offering to do injury. The ac companying photograph shows a family of Gila mon sters, consisting of two full-grown ones and a lizard sters, consisting of two
about four months old.

\section{Automobile Omnibuses in Berlin.}

The automobile omnibus system for passengers is now running very successfully in Berlin, and that city is ahead of most of the capitals on the Continent in
this application of the automobile. The Omnibus Com

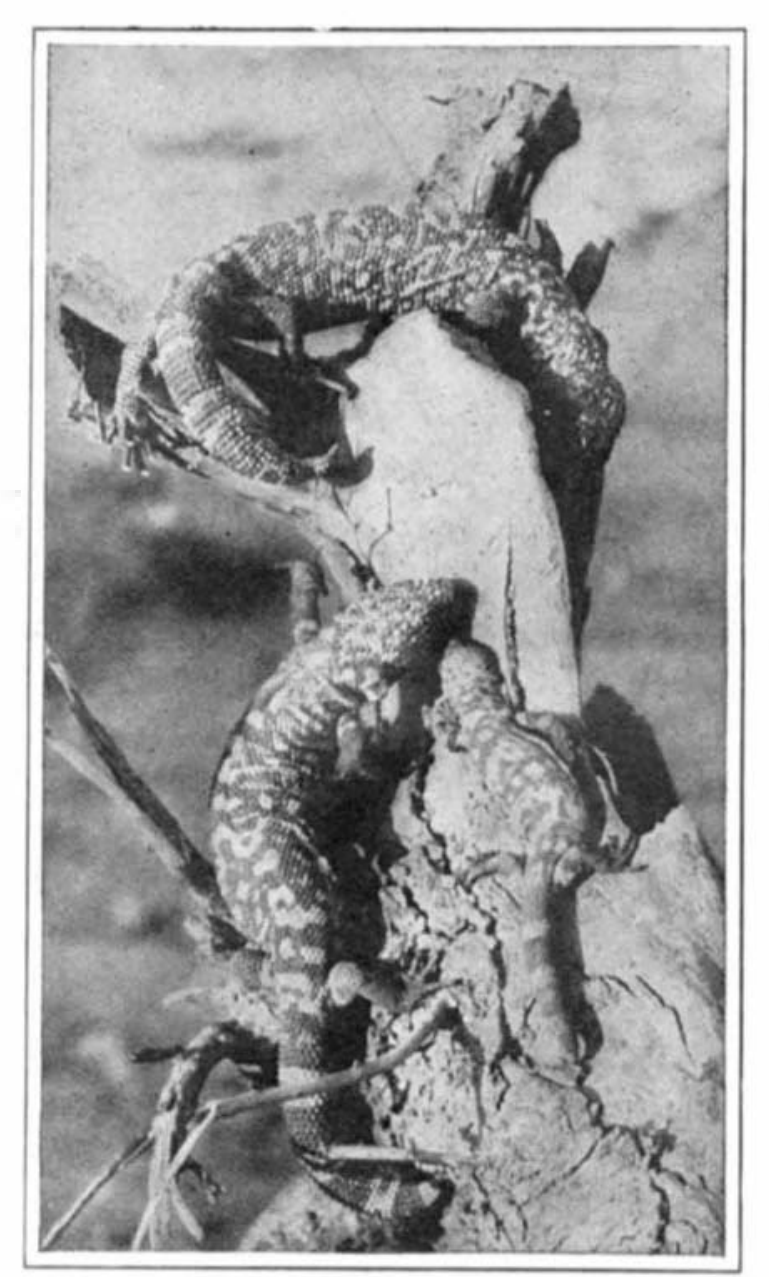

A FAMILY OF GILA MONSTERS.

pany, of Berlin, recently made propositions to the municipality, which were accepted, regarding a uniform rate of 10 pfennigs $(\$ 0.025)$ for all distances of the route. This rate is exceptionally low, seeing that all the new omnibus lines which have been put in operation have a length of over three miles. Some of the lines are nearly four miles long. Only the Schloss part-Charlottenstrasse line is an exception as to length seeing that, it is not more than $11 / 2$ miles in length. In this case the rate will be $\$ 0.038$ for the whole distance of the line and $\$ 0.025$ for fractions of the dis tance. Paris has been somewhat behindhand in the use of the automobile omnibus. At the last automo bile show a number of the leading makers brought out a form of omnibus which was designed after the stan dard city type. The Compagnie Générale has been fhe cars ever since then, and it is expected that tion.

The Prussian Ministry of Public Works calls the at tention of the several railways to certain defects which have been found in the superheated steam locomotives, and of the means taken to remedy them. In the steam chest of the Schmidt superheater the projecting ends of the steam tubes rust easily, and the crown plates of the superheating chamber become distorted and leak. To prevent rusting of the tube, ends one railway has introduced drainage channels with valves into the steam box, and these valves open when steam is cut off. It has also strengthened the crown plates.

\section{MODERN BELL CASTING.}

After having attained a high stage of perfection at the end of the middle ages, the art of bell casting rapidly declined in modern times, and was not restored to anything like its previous standing before the beginning of the nineteenth century.

It should be borne in mind that the tone and harmony of a bell are mainly dependent on its proper shape, which is determined by accurate calculation. There are mainly three types of bell profile, viz., first, the "heavy" profile, being of Dutch origin, and which has been introduced into Germany by some artists of the middle ages. The "Gloriosa" in the cathedral of Erfurt is the main representative of this type of bell. In towers affording ample room, this is preferred to all others, especially for large bells. The type of profile most generally employed in Northern Germany is, however, what is called the German or "intermediary" profile, allowing equivalent effects to be obtained with a smaller expenditure of metal. Such bells, having more elastic walls, are more readily actuated, without requiring the heavy clappers of the former. It should be mentioned that in the case of the same weight, the pitch of the German type is about one tone lower than that of the Dutch bell. The third and lightest type of bell is of less importance.

Among the most famous modern representatives of the art of bell casting should be mentioned Messrs. M. and 0 . Ohlsson, of Lübeck, who about thirty years ago came from Sweden to Germany, there to introduce the family art inherite from their grandfather and kept a secret through generations. By the courtesy of these process of bell casting as carried out in their foundry.

The first and most extensive and laborious part of the work consists in preparing the molds. In our illustration the casting pit in front of the furnace is seen still open, containing the core of a large bell, which has just been erected from red brick. The pit is more than $61 / 2$ feet in

The core corresponds to what will be the hollow in the interior of the ready-cast bell. This core is first coated with loam, to which is imparted an accurate circular form by the rotation of a board, that lengthwise is shaped like half the cross section of the future bell. This pattern obviously cannot be made before calculating and designing the accurate shape of the bell. On the core is next slipyed "what is called a "false bell" of loam, accurately agreeing with the future bell as to its shape and thickness, and which is provisionally to replace the latter, being intended afterward to be withdrawn. The loam layers this false bell is made up of should accordingly be readily lifted from the underlying core. To allow of this, the loam of the core is coated with a watery pulp of wood ashes. If everything has been thoroughly dried by a fire made up in the hollow interior of the core, the false bell will be readily lifted at the right moment.

After accurately shaping the false bell with the aid of a wooden pattern, it is coated with tallow, to which any inscriptions and decorations are applied. The tallow coating prevents the false bell clinging to the third and last part of the mold, viz., the shell. (An addition of graphite, brick dust, and many other substances will, by the way, serve the same purpose.) After the first layer of the shell has been dried, a second and third layer and so on are applied, continuing until the shell is of sufficient strength. In order to increase its durability, the shell should be surrounded with hemp and iron ties.

As every layer must be thoroughly dried before ap. plying the next one, in order to enable the mold to resist the enormous heat and pressure of the incandescent metal, the work proceeds only slowly and gradually. In order to utilize the time to better advantage, several bells are therefore in most cases molded at the same time.

Before proceeding to the casting operation, the shell should be lifted by means of a crane, and the false bell placed underneath be crushed. In fact, after helping in the shaping of the shell, it has fulfilled its purpose, and should be replaced by the casting metal. The shell is, on the other hand, replaced in position, and the crown containing the casting aperture (and which later on serves for the suspension of the bell) is fitted on the top. All fissures at the lower edge are carefully smoothed out, while the free space in the spacious casting pit containing the molds is carefully filled with soil, even the best-shaped shell being not resistant enough to 70 hundredweights of the hot melt. Leading from the casting furnace to each of the molds there are channels to guide the metal, while "windpipes" are arranged to allow of any hot gases escaping from the mold.

After everything has thus been carefully prepared, the casting day arrives, which is always a rather exciting one, even to the most experienced bell-founder, deciding as it does on the success of many weeks' or months' work, Early in the morning of that day the
furnace filled with copper is heated, long beech logs 
being ignited to produce a lively fire. Coal would not be suitable for this purpose, on account of the impurities it would leave in the metal. The flame are allowed to penetrate $\mathrm{through} \mathrm{a}$ choke in the fur nace, surrounding the copper, and thence getting to the chimney. I the chimn spite of mous heat, large wood $\operatorname{logs}$ are added continual. ly. Twent y - t wo parts of more readily melting tin are next added to the 78 parts of copper As soon as the melting process is thought to be sufficiently advanced, a small sample is tak. en from and crushed after cooling, when the shape of the piece will enable any experienced bell-founder to ascertain whether the proper mixture and temperature have been obtained.

The most exciting moment is when the metal is discharged from the melting furnace. A loam tap closing the aperture is crushed by means of a long iron bar,

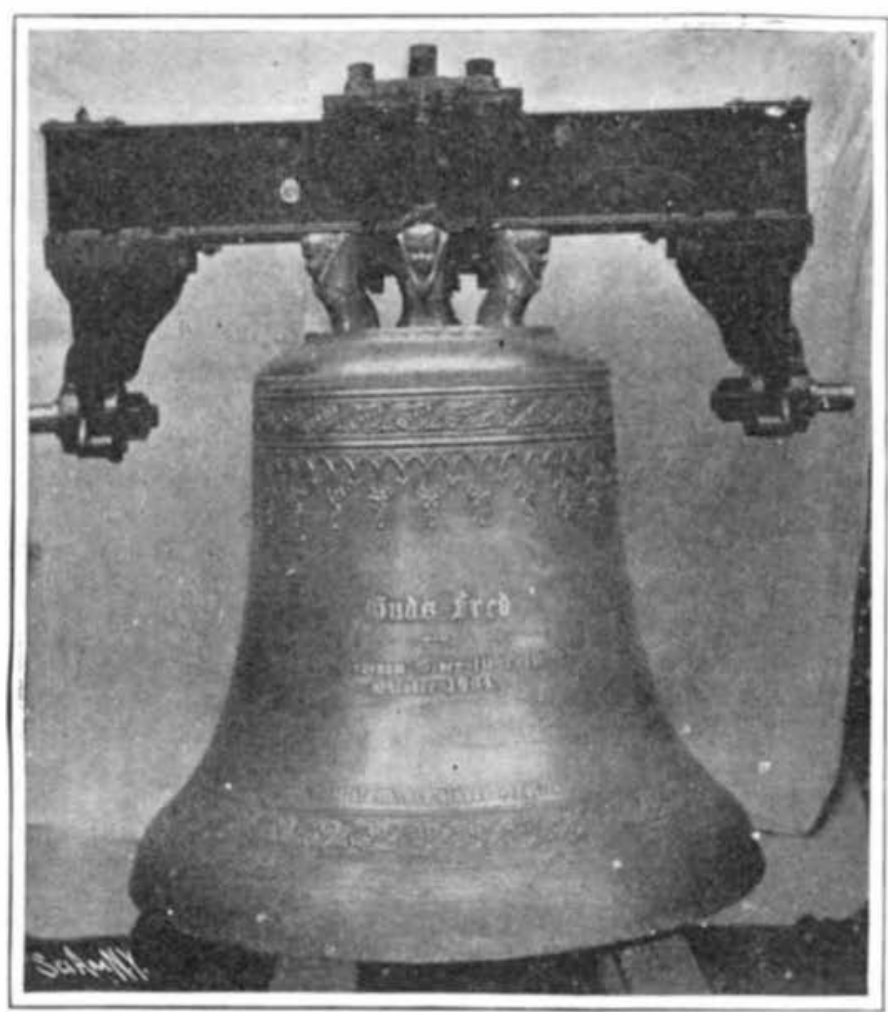

The Bell for the Free Harbor Church at Copenhagen, Showing the Balanced Suspension System.

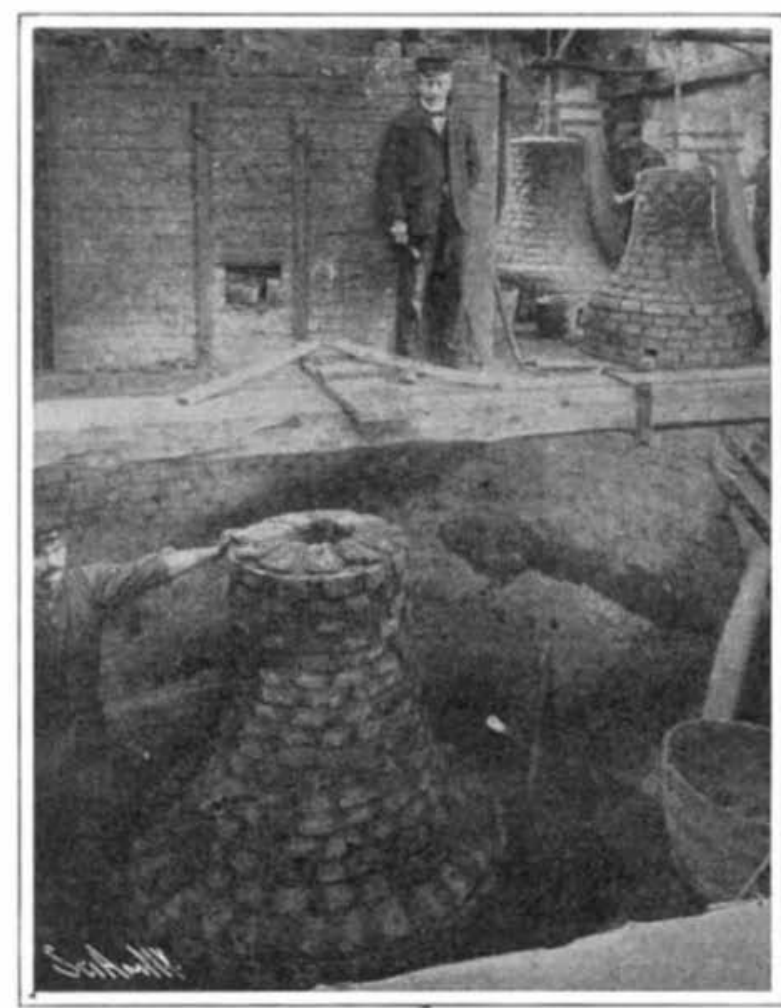

Casting Pit and Bell Core During an Early Stage of Forming the Mold. the bells are struck closer to the top, the sound is given off more fully. If the inverting points of the bells and clapper b e a $r$ t $h$ proper ratio to each other, the bells car be rung with half the expenditure of energy.

One of our engravings shows a bell which was recently cast for the Copenhagen $\mathrm{Free}$ Harbor Church, and which is the gift of an anonymous donor. This shows the just referred to.

A New Element

Some time ago it was announced that the university professor, Vattelli, of Pisa, had discovered a new element that is still more powerful than rabells are left in the soil for about a day, there to cool down, after which the soil being shoveled from the shells are removed, and the success of the operation ascertaine

An important featurc of a well-designed bell is its dium. We now possess details of this discovery, which has produced the greatest.sensation in scientific circles. Prof. Vattelli discovered a year ago in the waters of San Giuliano remarkable luminous phenomena. After numerous experiments he established that these waters suspension, the system mostly used by Ohlsson being are in a high degree radio-active. Then it was further

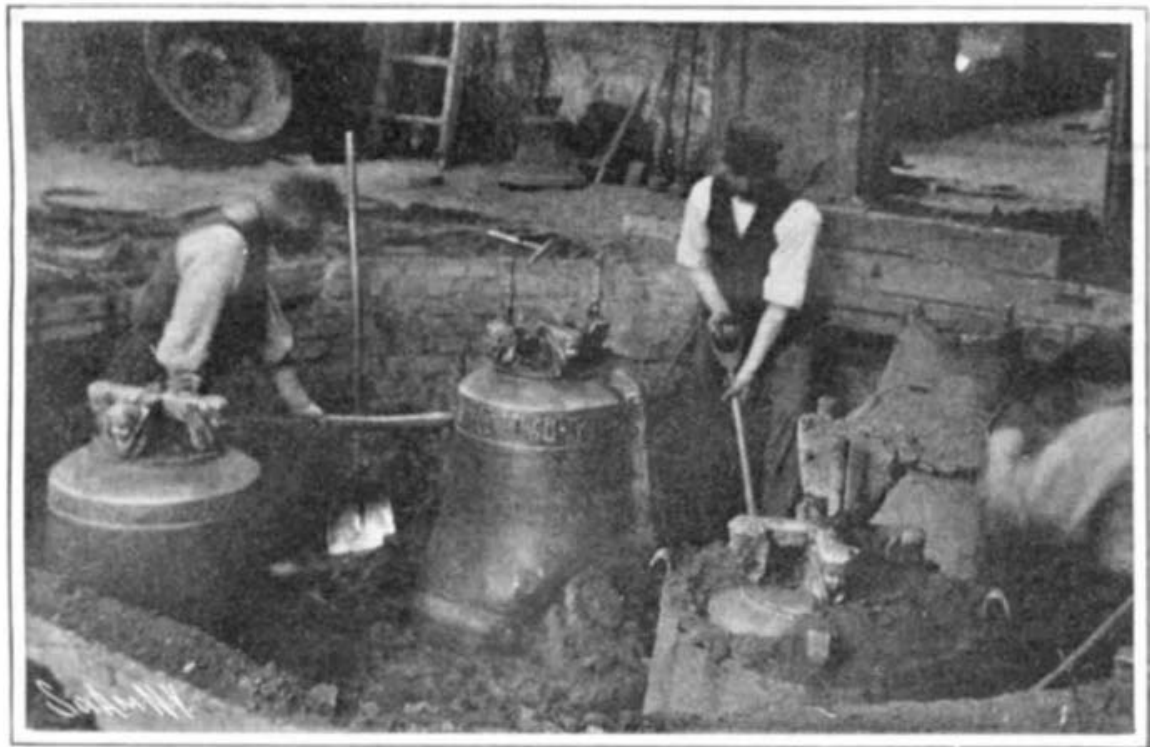

Digging Out the Cast Bells.

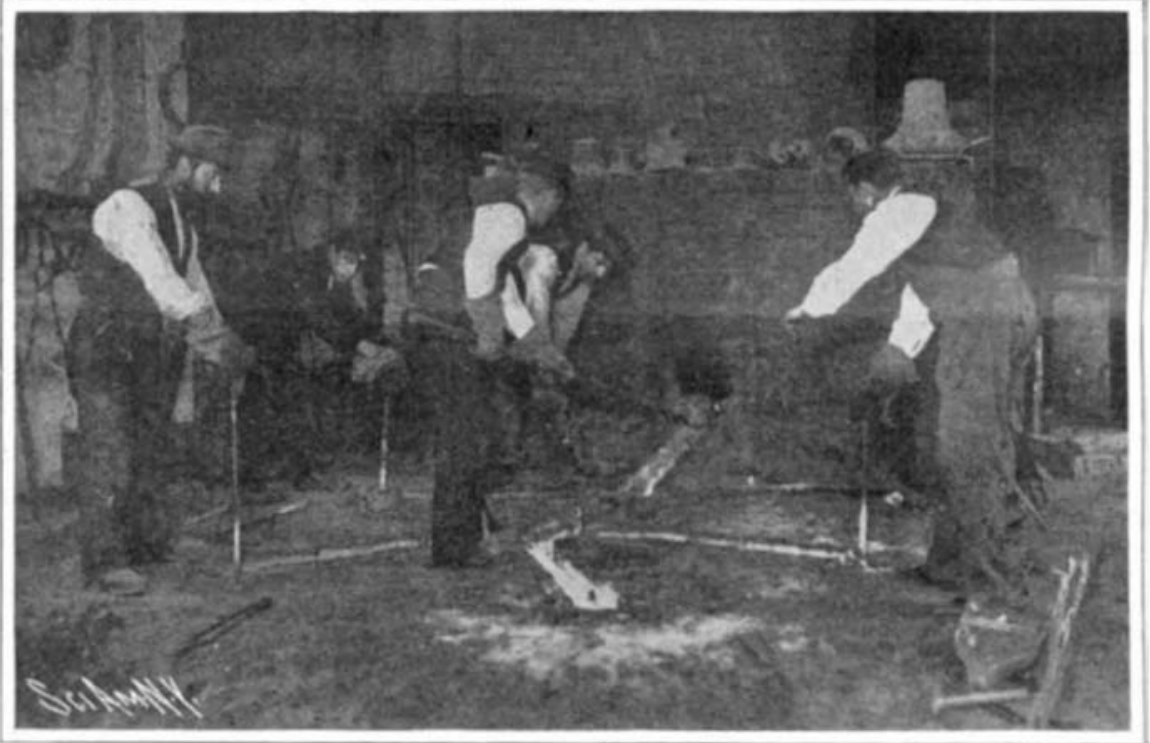

Running the Metal for Casting Five Bells. when the glowing metal like a'fiery current penetrates through the casting channel (which should be heated beforehand) into the first mold. The lively current of air issuing from the windpipe shows the mold to be filled, when a small sluice stopping the metal is rapidly withdrawn, and the second and third molds, etc. filled subsequently in the same manner. While the molding of the bells requires the patient work of weeks and months, the inflow of the bell is completed in a few moments. In fact, five bell molds are filled in no more than five and one-half minutes. All the workmen, being provided with enormous gloves to protect them against the unbearable heat, should be ready in the meantime to carry out every operation with an extreme swiftness. The most difficult is, however, the task of the master bell-founder, who should arrange everything with the utmost care, lest a large capital outlay be lost, and the whole of the work have to be started anew. The gases escaping from the windpipes are ig nited, burning with a gloomy flare which is said to produce a magnificent effect.

After the casting operation has been completed, the what is called the balancing system, which is based on the action of a wheel and rack. In opposition to the old method, the inverting point of the bell is, however, place higher up, thus allowing of an elastic stroke of the clapper instead of the bumping stroke which is quite unavoidable in a lower suspension. As

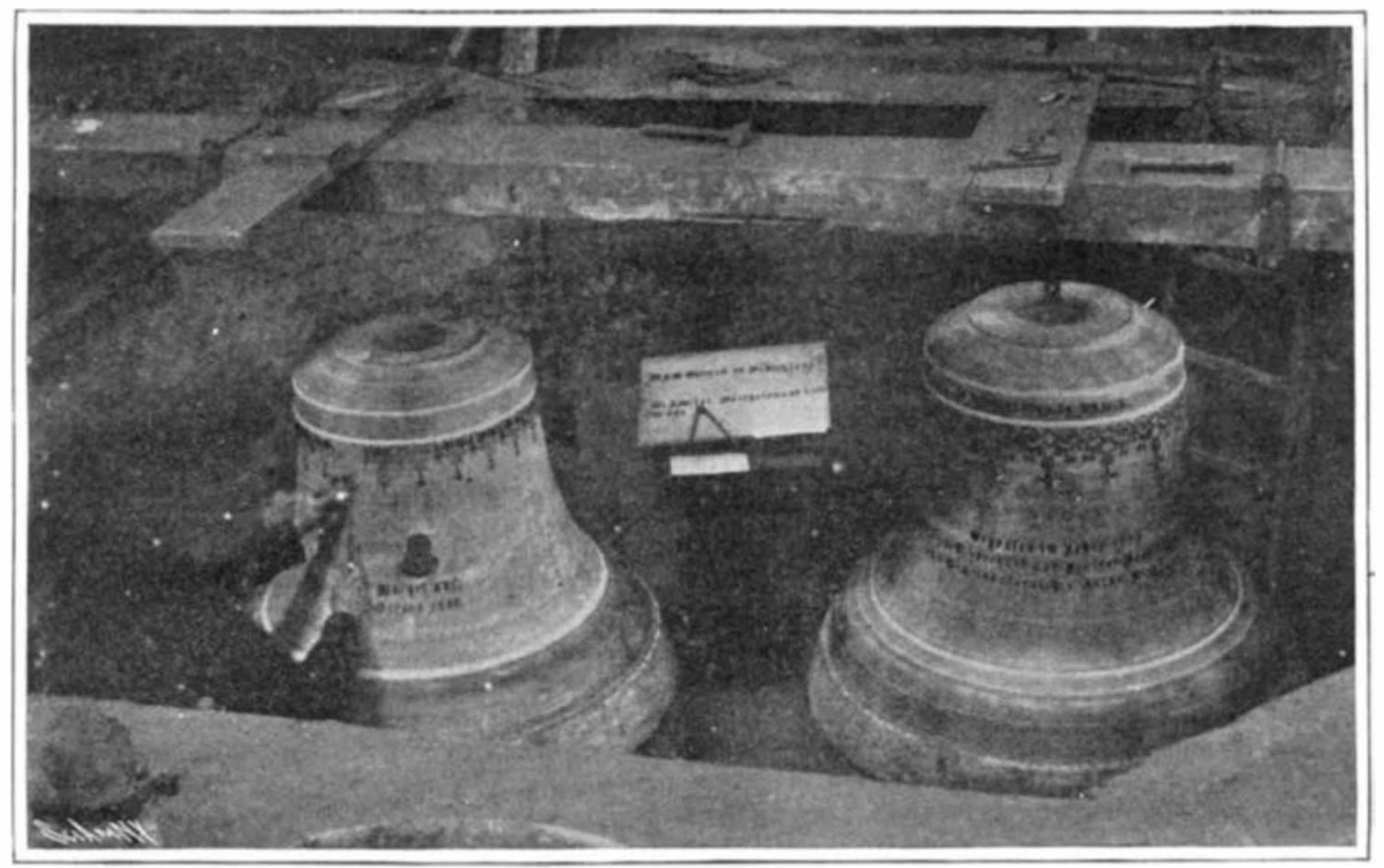

Fastening Decorations and Inscriptions to the Bells. MODERN BELI CASTING. merely a question of condensing the emanations. The condensing of the products of the radio-active substances occurs by their being treated exactly like gas. After being greatly compressed, they are collected in special tubes. That is a very expensive operation, and the new experiments in radio-activity. The gas, obtained in a very complicated way, after it had been purified was introduce inio small tubes dipped in liquid air and coated with aluminium paint. Here the condensed emanations at once became visible: they colored the aluminium wholly green. It cannot yet be said what kind of a substance it is from which these emanations proceed. But the mere establishing that they exist in great quantities in terrestrial water is a discovery whose bearing has not yet been discovered.-From New Yorker Staats-Zeitung.

Very good blue prints can be made from carbon copies on thin paper, if two sheets of carbon paper are used, one under and the other over the sheet which is to be printed from. Of course, both coated sides of the carbon paper are to lie next this latter. 